\title{
Innovation, Digital Solutions and MaaS Concept in Touristic Insular and Rural Destinations: The Case of the Shared Mobility Agency in Elba
}

\author{
Saverio Gini and Giorgio Ambrosino
}

\begin{abstract}
This chapter aims to describe the role of innovation and digital solutions in facing the mobility needs of the rural areas and tourist destinations and, at the same time, to discuss the problems and conditions for their use in the provision of the different mobility and transport services. Innovation in the mobility provision chain is analysed in relation to the relevant service elements (schemes, planning, programming, evaluation and support) in order to clarify that innovation does not automatically mean digital solutions. An overview of the emerging trends in digital solutions is provided, focusing on the Mobility as a Service (MaaS) concept and mobile applications. For the APP, market-specific considerations are developed on the different roles and typologies, making a classification for understanding current Mobility APP "Jungle". Moreover, the concept of Shared Use Mobility Agency (SUMA) is presented. SUMA aims to integrate smart mobility services under the concept of MaaS in order to answer to the mobility needs of residents and tourists acting on the demand and providing coordinated collective and ridesharing transport services. SUMA could be considered an "innovative" approach mixing advanced digital architecture and shared mobility schemes with the relevant organization, operation and business elements. Section 5 presents the SUMA implementation in Elba island (Regione Toscana-Italy), within CIVITAS DESTINATIONS project underlying the specifications of the platform and APP. Finally, besides the specific recommendations provided in each section, key recommendations for Mobility Authority and Transport Operators are spotlighted.
\end{abstract}

Keywords Ridesharing services • Info mobility • Innovation • ITS •

Digitalization $\cdot$ MaaS

\footnotetext{
S. Gini · G. Ambrosino ( $₫)$

MemEx srl, Livorno, Italy

e-mail: giorgio.ambrosino@memexitaly.it

S. Gini

e-mail: saverio.gini@memexitaly.it
} 


\section{Abbreviations}

$\begin{array}{ll}\text { FTS } & \text { Flexible Transport Services } \\ \text { IT } & \text { Information Technology } \\ \text { ITS } & \text { Intelligent Transport Systems } \\ \text { MaaS } & \text { Mobility as a Service } \\ \text { PT } & \text { Public Transport } \\ \text { PTA } & \text { Public Transport Authority } \\ \text { PTO } & \text { Public Transport Operator } \\ \text { SUMA } & \text { Shared-Use Mobility Agency }\end{array}$

\section{Introduction}

Mobility demand is becoming increasingly flexible in terms of users' segmentation and needs (both residents and tourists), transport mode, travel time. People are always on the move (work, education, leisure, health, etc). Connected mobility, involving Information Communication Technology (ICT) and Innovation, emerged considering mobility services as a seamless offer in terms of coordination of different modality and support service schemes, easy virtual and physical access, integrated payment and use of services irrespective of the mode and the operator. Users want to increase their flexibility in their choice of transport modes, but not being penalized in terms of accessibility, information, tariff schemes and costs. Some H2020 European projects have analysed these trends as CIPTEC (http://ciptec.eu) and MINDSET (http://www.mind-sets.eu/). On the one hand, these mobility trends could probably modify the future car use approach; on the other hand, they have already driven the growth of alternative ridesharing schemes.

On islands with rural areas and small towns, mobility choices of residents and tourists are limited compared to those in urban areas. Urban areas have been arranged so that people and all their needs are in proximity. In rural areas, destinations and activities are more diffuse, and the mobility solutions that work in urban areas are often unaffordable or unsuitable. In rural areas, it is hard to provide Public Transport (PT) services that are strictly tailored to the mobility needs of the various user groups (including the tourists) as demonstrated by the low use rate of PT services. The result is that small islands, small towns and rural areas become even higher car-dependent. The inevitable outcome is that cars are mostly used also for tourist travel. This is clearly incompatible with policies that seek to develop sustainable mobility for residents and tourists.

Last but not least, COVID-19 pandemic has added other trends affecting the demand: during the lockdown, mobility has been reduced to minimal activity and the prospects for recovery of user demand remain uncertain, with first data gathered in the Post-COVID period demonstrating a very slow growth. This can result in an excessive financial burden on traditionally lower demand services. While active modes such 
as walking or cycling might replace some of the trips by PT, there is the risk that many users shift to an unsustainable mode such as a private car (also for leisure and touristic trips). The Post-COVID protection measures (i.e. limited capacity on the vehicle, social distancing at the stops/terminals, etc.) add new constraints to the capability of "conventional" PT to be really effective in answering to mobility needs (becoming more differentiated in terms of time, places and target groups).

The COVID-19, therefore, has hugely impacted the transport sector with the risk of "new rise" of private car use also provoking new needs and other different options at the level of tourist destinations like the following ones:

- The municipality or the association of Municipalities needs to come back to a central role in Public Transport and collective services;

- Rethinking the space management policy in order to guarantee dedicated spaces to collective transport and active modes;

- Integration of occasional fleet in public transport service, ride/asset sharing schemes and personal mode (active, clean);

- Operation of a low-cost platform for control, coordination and reporting transport services offered in one or more areas;

- Operation of tools for monitoring the different services and providing specific services to the different user groups (residents and tourists);

- New partnership and business model for supporting the main mobility components (being the Agency one of these).

The above aspects push more the role of digitalization and the connected mobility in the policy and solutions for rural mobility, including also the tourist destinations.

The following Sect. 2 outlines the main mobility problems and needs concerning the role of innovation in transport services provision with respect to the other basic elements like mobility schemes, user information. Section 3 provides a picture of the emerging trends in digital solutions is provided, focusing the Mobility as a Service (MaaS) concept and the mobile applications. For the APP market specific considerations are developed in Sect. 4 on the different roles and typologies in order to face the current Mobility APP market, always more similar at a "Jungle". Moreover, the concept of Shared Use Mobility Agency (SUMA) is presented. Section 5 presents the SUMA (Gini, 2019) implementation in Elba island (Regione Toscana-Italy), within CIVITAS DESTINATIONS project in terms of needs analysis, design, implementation, organization and business model aspects. Finally, in Sect. 6 some key recommendations for Mobility Authority and Transport Operators are spotlighted. 


\section{Key Mobility Aspects}

\subsection{Mobility Demand and Transport Schemes}

The role of PT services, as emerged by the initiatives and practices around Europe, independently of the operator (public, private or public-private partnerships), is the key tool for facing not only the mobility problems but also for supporting the citizens day life with different role in relation to the different areas (rural/peripheral areas, small-medium towns, metropolitan city, etc.) and transport demand requirements and segments.

PT, especially since the last decade, is changing its offer in terms of service schemes/options (e.g. demand responsive, ridesharing, targeted services, etc.), customizing them to the local needs and specific purpose/target clients and operating them as last-mile/feeder of the "conventional" services (serving primary axis/connections). Although public and private sector stakeholders need to cooperate in order to address challenges regarding regulation, insurance, business models and equity, shared mobility (asset and ridesharing), services can improve the accessibility of targeted areas, thus they need to be integrated into the whole mobility offer. It might be that Public Administrations and PT/Mobility Agencies take the lead in exploring the modalities of coordination/cooperation, playing a leading role in defining the framework and solutions.

From the demand side, a mobility offer restructured as above described, allows the engagement of potential customers who are available to use PT on an occasional basis by combining this choice with other possibilities; in a short time, the frequency of PT use can be increased. On the contrary, Public Authorities (Municipalities, Mobility and PT Agencies, etc.) usually consider the uptake of ridesharing services as a substituting solution for PT than as an integration element.

Ridesharing services cover a broad range of flexible and intermediate individual and collective transport modes: from dynamic ridesharing services to peerto-peer transport schemes and new forms of "institutionalized hitchhiking" to well-established schemes like bike and car-sharing to collective taxi and carpooling.

From the service point of view, models promoted by ridesharing services under the "DRT or Flexible Transport services" concepts which have been already implemented from the 90ies by PT operators and authorities. Flexible Transport Services (FTS) could be adapted for meeting user needs, typically on a trip-by-trip basis with flexibility on three operational service parameters (routing, timing, vehicle used) to enhance service in response to demand. FTS include a wide range of services and schemes, such as general use, local and feeder services to trunk haul, replacement of low-frequency conventional services, service in low-demand periods, special services to specific users' groups, services in low-density rural areas, efficiencies in social mobility resources, niche urban markets, fuzzy lines between small buses and big taxis, etc. These services and schemes could be supported by the last decade improvement in digitalization and connecting devices. 


\subsection{Innovation and Digital Solutions}

In collaboration with other initiatives as SMARTA project on shared mobility solutions in rural areas (https://ruralsharedmobility.eu/) project, based on the analysis of the different involved Pilot sites and the related mobility and technology solutions, a more in-depth discussion was dedicated to understand the correct relation among Innovation and Technology in Mobility and Transport services covering also the role and responsibilities of different stakeholders involved in rural areas and tourist destinations.

Very often, especially from the local public stakeholders, the approach to the innovation is based on considering the digitalization as the solution instead as a tool or enabler element for setting most suitable solutions answering to the identified mobility needs of the different user groups (tourists included). Moreover, if the identified solution is "digital", many times the choice falls on pure innovative advanced tool rarely applied in real operated service rather than on a stable and consolidated system. The innovation should be closely tuned to operation situation (not only from the PT and mobility services), characteristics and objectives of context areas considering the needs and requirements of the different citizen groups. Therefore the "Innovation", especially for mobility and transport services should be turned in different aspects of the service provision chain as the following ones: planning and engagement, business model and marketing product and service schemes, priority and impacts, etc. Innovation should be also considered based on the emerging scenario with a mobility demand more erratic and less systematic, increasing role of transportation network companies and asset sharing service operators, mutual interrelations among tourists and residents needs and requirements, decision-makers much influenced by digital solutions and social media.

As we analysed during DESTINATIONS implementation phase, some sites defined small innovative measures that allow facilitating the PT services and the use of active modalities, some other sites realized digital platforms for informing the users and for integrating the management and payment of the service. "Innovation" is not a unique definition and should be declined with respect to the objective of the city and the needs of the "users" groups. In the context of Mobility and Transport services for tourist destinations and rural areas, the Municipality can "innovate" "only" with the extension of the collective services and the improvement of the related quality through the implementation of shared mobility services in order to increase the flexibility of the overall mobility offer. The above "innovation" approach should be realized also with digital solutions, but surely the key role is played by the Bus, the first "type" of ridesharing service. 


\subsection{Lack of Integration of Mobility Services}

The mobility offer even based on "different" type of innovation has not been yet fully able to answer to the problems and emerging trends described above.

Focusing on the integration of transport services/offer, one of the main aspects that emerged from the DESTINATIONS sites are the following:

- Lack of policy and methods for planning the standard transport services and shared services on the basis of the different needs of the user groups and area characteristics;

- Poor coordination among different mobility operators and lack of multimodal options/solutions;

- Poor collaboration among public and private operators in order to offer complementary services (Demand Responsive Transport, sharing and active modes, ...).

Therefore, as explored in Elba island, the setup of an integrated mobility offer requires the implementation of "tailored" flexible services customized to the needs of the target area and users; the flexible services should act as "feeder services" in relations to the main PT routes or main connections, the coordination and the exposition of the overall differentiated offer carried out by unique entity (Agency).

From the digitalization side, many relevant problems concern the network integration of the different solutions and systems (ticketing, control and monitoring, user info), although specific initiatives on data standardization and protocols have been defined at European and US levels mainly for the management static and dynamic service data. Moreover, the level of collaboration among the different actors/operators (public and private) involved in the transport service provision chain is still very low (or difficult to realize) impacting negatively on the level of intermodality and interoperability of the services. The main challenges are related to the holistic service management, business model, common tariff scheme, commercial agreement, revenue reporting, accountability, etc. All these aspects require a key role of mediation and coaching of the Local Authority that beside fixing the regulatory framework for the different services (transport fleet, mobility service, parking, etc.) should plan a coordinate mobility offer among the conflicting needs of the different operators.

In this context the main issues emerged during the DESTINATIONS implementation for improving an "integrated" and users-responsive mobility offer requires different interlocking dimensions:

- Acting on regulation, focusing on a specific PT and shared regulatory framework (which in various EU States is lacking);

- Developing new service concepts to meet evolving needs;

- Identifying the markets these will serve and the transportation function for each;

- Identifying, developing and deploying appropriate technical solutions to deliver the services; 
- Developing the business case for the foreground and background services, defining appropriate commercial agreement among the involved operators in case of integrated payment;

- Defining an appropriate organizational framework for delivering transport services. In particular, with regard to the operation of ride and asset sharing services for specific areas and specific user needs;

- Establishing specific private-public-no-profit cooperation schemes for the operation of the services.

The above aspects have been faced in Elba with the implementation of the SUMA concept (Ambrosino \& Gini, 2018) and are described in Sect. 5.

\section{Last Decade Digital Solutions}

In the last 5-10 years, the domain of Information and Communication Technologies (ICT) has experienced a quick and uninterrupted growth in the number and in the deployment of solutions. ICT recent trends range from remote software platforms (i.e. i-Cloud solutions for data retrieving, storing and management) to platforms/solutions for the integration and management of data generated by different systems and sources, from mobile applications and hand devices to the improvement of wireless communication networks, etc. As a result, in the mobility sector, Intelligent Transport Systems (ITS) deal with the deployment of new emerging solutions implementing new digital services for users/stakeholders, or offering consolidated services under innovative approach/accessing tools: from integrated platforms for the monitoring and management of transport resources and events to info mobility systems on SMS/mobile, apps/web portal, integrated payment systems (via SMS/credit cards/smart cards or electronic tickets, etc.) and support systems for service operation (fleet monitoring, traffic lights priority, etc.).

ITS have increasingly caught the attention of Public Agencies, Public Transport Operators, and mobility stakeholders: this interest has grown in parallel to the most recent ICT solution developments, driven by the perception that improvement of hardware/software solution performances and the enhancement of communication networks can immediately boost higher performances of ITS systems, allowing the introduction of new customer-facing services and, at the same time, decreasing the amount of human resources required (e.g. in on-street control and administration functions). Underpinning this is that all these factors produce significant economic savings for mobility stakeholders (in particular Operators) and, in general, a drastic cut of allocated public resources.

While this potential certainly exists (and is well-achieved in a variety of cases), it is necessary to pay a high attention to this point. The actual experience with ITS applications in a wide range of countries is that the expected performance and/or benefits are often not fully achieved, due that operational and organizational impacts produced by ITS and related costs are often underestimated. 
A "key example" is the provision of multimodal real-time information on traffic and transport services operated in an urban or metropolitan area. These services are provided via web portals and mobile applications and are now rather frequent in many European and non-European towns. As already stressed, this trend is driven by the recent developments of solutions for the integration of data generated by different systems and tools (webservices, $\mathrm{xml}$ ), the growing impact of standardization solutions for data geocoding (WSDL, WMS, WFS, etc.), data formatting and exchange (i.e. at European level: TRANSMODEL and SIRI for Public Transport data, DATEXII for traffic data, etc.) and the availability of technological solutions enabling an "always-on" approach to information access (smartphones and tablet, mobile app, web 2.0, etc.) to users. This kind of systems are able to access data from different sources (systems operated by different operators/stakeholders), aggregate and elaborate them for the provision of added value services: static and dynamic info on PT (timetables, location of stops, lines description, real-time arrival time of vehicles at bus stops, etc.), parking info (location, total number of lots, real-time availability of free lots, etc.), traffic events (road works, modification to the network, real-time identification of road sections with traffic congestion), flexible services (location of bike stations, real-time availability of free lots for bike, location of car-sharing and booking status of car-sharing vehicles), location of recharge points, multimodal journey planner and tickets payment.

Finally, besides the great opportunities of digitalization, some challenges need to be addressed, both technical, such as data collection issues, interoperability, scalability and information security, and non-technical, such as business models, usability, privacy issues and deployment.

\subsection{Development of Mobile Technologies}

Mobile technologies have an impact on both demand and offer side. Customers (demand side) want mobility services that meet quality standards as other services do. In response, stakeholders (offer side) adopt new approaches in their relationships with customers increasing services for mobile technologies and platforms, such as infomobility (e.g. multimodal apps etc.), payment (SMS, QR code, NFC etc.), customer care (e.g. use of social media, customer requests, customer satisfaction surveys) to engagement processes (e.g. online questionnaires). The rapid growth of MaaS initiatives aims to provide customers with an integrated offer that can be accessed based on their specific needs.

\section{2 "Virtual" and/or "Remote" Platforms}

The availability of "virtual" and/or "remote" platforms allows for re-design of flexible PT/mobility schemes in a way that has not been entirely embraced by Public 
Authorities/Operators, instead of being primarily led by NTC providers. Innovative mobility services combine flexible schemes with traditional technologies, with new capabilities offered by "remote" platforms. Large benefits in optimizing resources and reduce cost impacts (both for investments and operation) could be achieved by exploring the possibilities for aggregating and networking different Operators in an integrated mobility offer through "virtual" platforms. New services can be more financially sustained if shared between operators or made accessible through "Service as a Solution" (SaaS)".

\subsection{Open Data/Standardization}

Open data and standardization foster the exchange of data among different actors (Mobility Authorities, Public Administrations, Mobility Operators, IT providers, etc.). Open data trend pushed the development of "added value" services (i.e. pretrip/on trip information including static and dynamic info, interoperable payment solution such as credit card payment) for the customers and contributed to break down the market, giving the possibility to any IT provider to implement their applications in a competitive and fair way. Furthermore, both open data and standardization improve the fair and transparent flow of information between mobility stakeholder and external actors. From the perspective of Mobility stakeholders, the standardization of data format contributed to create aggregated data sources both at the level of a single organization (i.e. combining data generated by ITS implemented by different IT provider) and at the level of the served area (i.e. combining data produced by different Operators). Aggregated data sources are the pillar for the introduction of "data mining" tools to leverage the "business-oriented" approach of mobility sector: service planning optimization, tuning of operational procedures efficiency, assessment of service performance as a baseline for the definition of improvement targets, etc.

\subsection{MaaS (Mobility as a Service)}

MaaS (Mobility as a Service) concept emerged with aim to solve the current fragmentation in ticketing, info, marketing, accessibility and cooperation among different mobility services and operators. MaaS can be defined as the transition from a dominant car-ownership model of mobility, to one of paying for mobility "on account" using more sustainable modes of transport as an alternative to private car use (Hietanen, 2014). With MaaS, individual transport needs (usually satisfied by car), are instead met by a range of services such as car leasing, car clubs, carpooling, community transport, bike and taxi services in combination with "traditional" PT services. MaaS concept in any case has been developed mainly on urban/suburban areas. 
E-ticketing, AVM and User information systems are the base systems for any MaaS concept implementation. In Europe, it is common that, these systems are designed, contracted and operated under the responsibility of PT Operators or Agencies but not always they are planned under a "city approach". These systems are often designed individually and their integration must be carried out on a "bottom-up" approach.

The role of PTOs is fundamental in MaaS as PT services are the backbone in terms of data provision, responsible for system operation and management and for assuring the quality and reliability of services on the road. None high-quality MaaS service will be possible without an efficient and integrated PT offer and without the certification of the data quality provided by the base-level ITS.

The operation of a wide range of ITS dealing with MaaS must guarantee high system performances and strong reliable of services and data. To achieve these objectives, the involved systems must be operated with a well consolidated organizational structure and proper operational procedures: suitable data certification procedures are required and high-quality data must be assured by each Operator based on contract terms and related rules which should be issued by the coordinator of MaaS initiative (EMTA 2019).

In any case, the experiences on MaaS realized until now are related to urban context like large or medium-size towns with PT operated under the direct responsibility of Public Authority. The MaaS concept in rural area where the PT offer is very low and based on different mobility schemes and operators is still unexplored for the lack of a relevant demand and for the fragmentation of existing mobility demand.

At this stage after almost 10 years since the launch of the MaaS concept some considerations can be summarized as the following ones:

- There is not a unique MaaS definition, each stakeholder or market provider has a specific definition and implementation of MaaS concept;

- MaaS is a process to be realized gradually depending on the context mobility objectives and the existing systems/services;

- The risk is to use new "acronym" to hide unsolved challenges: organization, operation, service quality, commercial deal aspects, contract management and system reliability monitoring;

- It is vital an effective cooperation among the different Authorities/Operators responsible for the different systems and services under the indications of the ITS EU directive;

- The role of ICT/system providers is not secondary and they should be involved in the engagement and cooperation process.

The above considerations bring also to highlight some issues or questions that should be faced for consolidating the MaaS concept like the following ones among the others: Which regulation framework for the service provider? How to guarantee the quality of involved services? How to guarantee quality of system data production? How to appoint specific systems in MaaS in terms of performance indicators? Which role for the PP Partnerships approach and related business model? 
A tentative to facing some of the previous aspects and question has been carried out for the rural and tourist areas with the implementation of the Shared Use Mobility Agency, described in the section below and detailed in Sect. 5.

\subsection{Concept of Shared Use Mobility Agency}

The SUMA concept aims to reconcile and enhance two parallel axes of mobility services (collective transport and asset/ridesharing services) by common planning, coordination, management and integration of the different innovative mobility solutions.

Both public (collective) and private levels interact with each other: major transport axes and corridors on one hand, and flexible/ride/asset sharing services on the other. Fostering the interaction between public and private mobility through various connected mobility schemes (parking, Park and Ride, interchange facilities with shared vehicles' schemes, integrated payment, etc.) is pivotal for improving mobility as a whole.

Effective integration between collective and shared mobility is achieved by working on three interrelated levels (collective transport, personal mobility and connected systems). SUMA offers integrated access to several "on-demand and shared" individual and collective services, by coordinated management of the various actors and services through an ad-hoc organization framework, technology-enabled services and soft measures.

SUMA also acts as a base for any MaaS initiative tailored to mobility demand and the territorial context and the needs and requirements of citizen groups (Ambrosino \& Gini, 2016).

\subsection{Key Role of Mobile APP}

Despite facing different problems, objectives and approaches, all the above scenarios and trends objectives and approach give a central role to Mobile APPs and this role is differentiated for each digital solution.

In this context, the emerging APPs in mobility and transport services are linked to the most recent ICT developments described above and they have the following objectives:

- to improve the overall PT marketing strategy, not only providing users with information on the services operated, but also establishing an innovative channel of communication and interaction with them (functionalities feedbacks);

- to collect service data for acting on the service operation and/or to evaluate the service planning and program compared to the real service behaviour; 
- to integrate information and services already available/provided in a number of separate channels/modalities, in order to create a unique "contact point" with clients and to optimize and enhance the technological investment already made;

- to build on the standardization and the modularity of the technological solutions, in order to allow the future extension to other platforms (web portal), other mobility services (also provided by other Mobility Operators) and to "Open data" publication.

In the last decade, many different APPs have been introduced in the market both by the transport and mobility operators and new emerging Transport Networking Companies (from UBER to MOOVIT). These APPs have different objectives and roles from provision of innovative infomobility for PT and mobility services to the integration of info and the provision of multimodal added value services, the identification of the mobility needs and the service coordination.

Usually, the transport operators are highly committed in the introduction of the infomobility to increase the quality of transport services provided to users and citizens, to improve the company competitiveness and to optimize/unify internal procedures for delivery of the services. As a result of this approach, many Mobility Agencies or Transport Operators manage a wide range of innovative services to provide information to users: info panels at bus stops and terminals, on-board monitors for next stops visualization and infotainment, PT trip planner and info on timetable, line diversions and relevant news on the web. In this context, the APP is identified, by the PTO/PTA as a new product for the enforcement of commercial initiatives addressed to customers and potential users accustomed to smartphone/tablets and mobile services (H2020 2018).

The APP implementation usually is based on a platform able to access a wide range of base data stored/generated by the other company systems/tools (database, applications, web services/file transfer), to update, integrate and elaborate such data in a common standardized layer (middleware) and to provide added value services on mobile devices (Android and iOS platforms) and web portal (future extension). The setup of the standardized middleware will be an added value in case of future extensions of the platform to other mobility services and the provision of "open data" to third-party B2C services developers. The APP is designed to manage data for the various service areas operated by the same PTO company and to be multi-language (Italian/English in the version already published but compatible with the extensions to other languages).

Also, in DESTINATIONS different APPs have been developed. Based on an analysis and classification of the APP Market, carried out in collaboration with SMARTA project, criteria have been defined for choosing the most suitable APP in the existing APPs "jungle". 


\section{APPs Jungle}

This section details the key issues to be addressed for the implementation of APPs in the mobility sector. Initially, a classification of the APPs is provided in order to set the main scenarios (Gini, 2019). In fact, when talking about APP, the term "service" indicates a function or a set of functions allowing the users to receive information on a specific mobility (or other sectors) services (i.e. real-time information on bus arrival, journey planner, etc.) or to make an operation (i.e. to buy the ticket). The use of the term "services" in such a context should not generate confusion with the mobility services which are operated on the network (e.g. Public Transport (PT) or demand responsive) producing information (data) for some APP functions (i.e. bus arrival delay).

From the technical point of view, the APPs operated in the real environment are usually a combination of two (or more) different categories presented here; nevertheless, the suggested approach is useful at the beginning of the design phase to identify the required functionalities and then to analyse the required data. The following three main typologies/categories can be identified:

- Class-A ("CA") APPs exposing information services (i.e. PT timetable, PT realtime information). For this category, the mobility/transport services (producing the data) are operated by a Public Transport/Mobility Operator in one or more areas (or Town, Province, Metropolitan areas);

- Class-B (“CB”) APPs exposing information services and allowing a wider set of end-users' services (e.g. tickets payment, journey planning, etc.). The services are operated by a Public Transport/Mobility operator in one or more areas (as in "CA");

- Class-C ("CC") APPs integrating data/services from/for different Mobility Operators (in one or more areas) and/or extending the end-users' services to innovative services such as crowdsourcing, management of relations with the customer, demand behaviour triggering (gamification), demand aggregation (ridesharing), feedbacks from the users (i.e. service quality assessment), O/D matrix estimation, etc.

\subsection{Exposing Information Services to the End-Users (CA)}

In order to easily describe this APP category, it is possible to focus "CA" APPs on those APPs whose services relate to a single Operator (the service can refer to one or more covered areas).

This type of APPs provides information services to the end-users, for example:

- Info on the scheduled service (static data such as timetable, graphical representation of the lines on the map, schematic representation of the line, list/map representation of the bus stops-pick up/drop off points, etc.); 
- Single-mode/service (PT) journey planner (eventually integrated with walking info);

- Info on the operated service (dynamic data such as the position of the bus on the line, real-time arrivals of the buses at the next stops, modifications of the operated service compared to the scheduling, line diversions, events on the network, etc.);

- General information for accessing and use the service (static data) such as a description of fare and tickets, list/map representation of the selling points, access rules to access the vehicles, procedures for reclaims in case of irregular service events, etc.;

- News links (to company or institutional websites), etc. This could include "external links" to other APPs or websites providing "CB"-type services (i.e. tickets payment).

MOOVIT $^{1}$ (Fig. 1) can be considered an example of this category, despite different Mobility Operators (Public Transport, asset sharing, etc.) are included and the APP allows also the collection of the notification/feedbacks from the end-users.

\subsection{Exposing Information and Providing Access to a Wider Set of Services $(\mathrm{CB})$}

As the category "CA", the "CB" category APPs still refers to the services provided by an Operator (in one or more covered areas). The "CB" category APP includes the type "CA" and provides the end-users also with access to a wider set of services, including:

- Tickets purchase through different modalities (SMS, QR code, bank card, NFC, different "wallet functions" available on the market such as GooglePay, SAMSUNG Pay, Apple Pay, etc.);

- Recharge of contactless smart cards or e-purse (directly via NFC or after the smart card is put near a validator or an Automatic Vending Machine);

- Booking/seat reservation.

TreviMove $^{2}$ (Fig. 3), the APP operated by Mobilità di Marca (the mobility Operator in the Shire of Treviso, Veneto Region) and Tiemme Mobile ${ }^{3}$ (Fig. 2), the APP operated by Tiemme (the Public Transport Operator in the Southern and Eastern part of Tuscany, one of the largest Italian PT operator) are examples of the "CB" category. Nevertheless, in the case of TreviMove, the services provided by the APP are extended to parking services which are operated directly by MoM in the urban area of Treviso.

\footnotetext{
${ }^{1}$ https://moovit.com/.

${ }^{2}$ https://mobilitadimarca.it/p/trevimove-app.

${ }^{3}$ https://www.tiemmespa.it/.
} 
Fig. 1 MOOVIT Graphical representation of bus stops and line with real-time arrivals
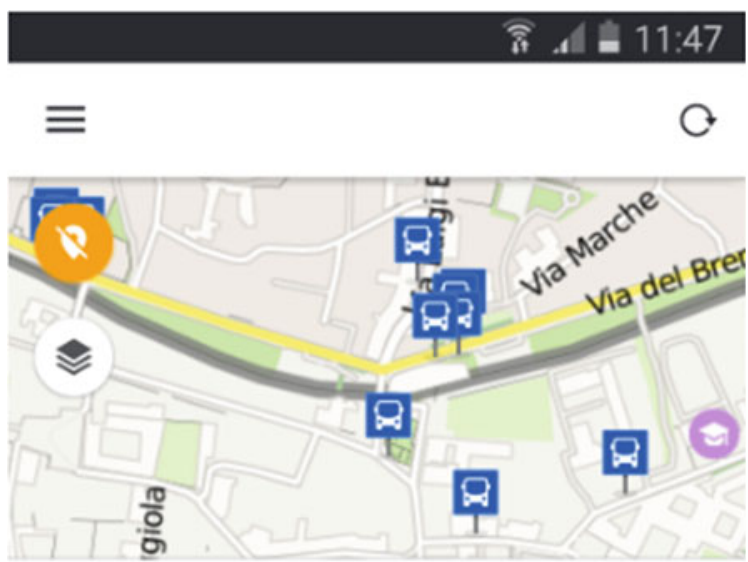

VICINE

PREFERITE

\subsection{Integrating Operators Services, Innovative Functionalities $(C C)$}

The "CC" category APP can network different mobility services (but also no-mobility services, as the tourist ones) and provide a broader set of services compared to the "CB" category.

With regard to the networking of different Operators and services, "CC" category APP provides the following "services" as examples:

- Integration of the static/dynamic information related to the services provided by different Public Transport Operators (PTO) in the same area(s), i.e. different bus 


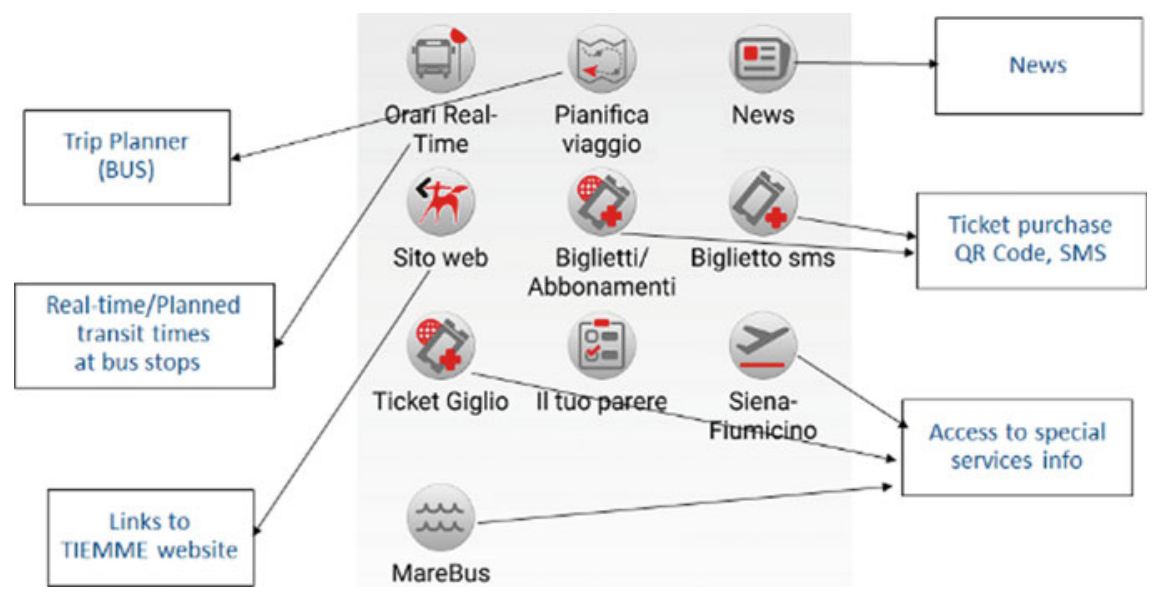

Fig. 2 TIEMME and key services

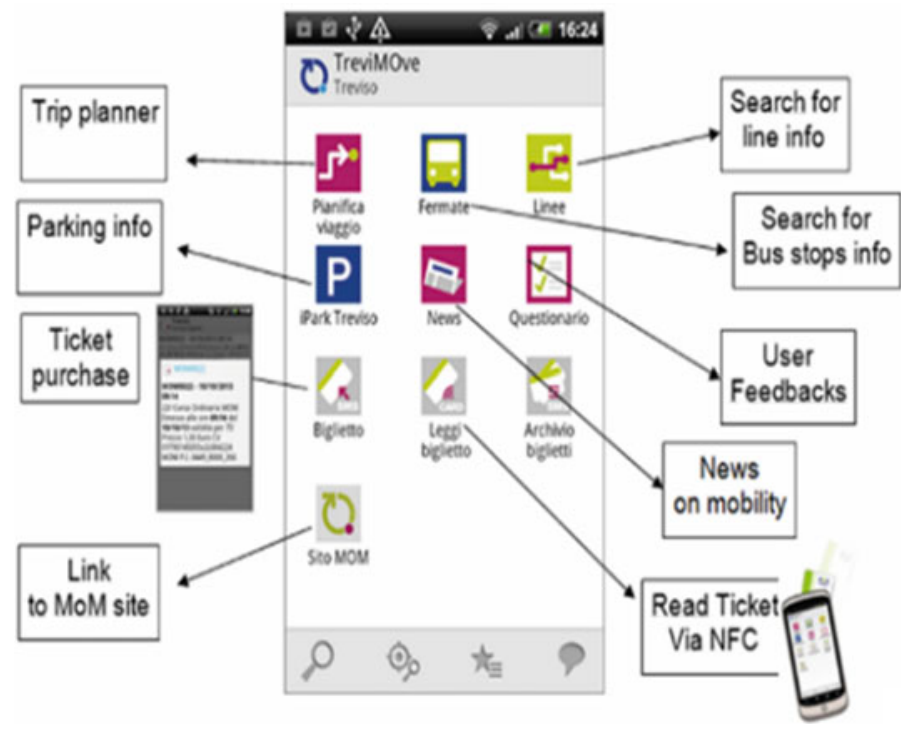

Fig. 3 TreviMOve key services/functions

Operators, conventional + flexible services + niche/dedicated services, bus + train, etc.;

- Integration of the static/dynamic information related to the services provided by Mobility Operators in the same areas (i.e. parking areas (location, number of available lots, occupancy, etc.), related to Park\&Ride services, bike-sharing as PT feeder, bike stations, rental (bike) operators, access restrictions to city centres, etc.); 
- Integration of static/dynamic services related to other mobility services (integrated payment - MaaS, booking of services package, etc.);

- Multimodal journey planner (private + PT, eventually integrated with info for cycle lanes).

As extension of the Mobility/Public Transport APPs, "CC" category can encompass info more properly related to tourism experience and overall accessibility/travel needs in the target area (i.e. asset sharing/rental operators including scooter or cars, hotel-bike service, list of tourist destinations, etc.) and the services can be extended in parallel (services for tourism accessibility, integration between mobility and tourism services, etc.).

Concerning the integration of innovative services, some examples are provided in the following:

- Interaction with on-board devices (eventually installed) for visually impaired customers;

- Collection of data by crowdsourcing initiatives (i.e. estimation of Public Transport O/D demand matrix through automatic detection of APP connections or registration of trip diary);

- Collection of notifications and feedbacks from the customers (online surveys for needs assessment, online questionnaires on the quality of service provided, suggestions for service improvement, etc.);

- Gamification/management of incentives (i.e. discounts for commercial products) to promote the use of sustainable transport modes and eco-friendly travel behaviour;

- Aggregation of the demand between customers and management of ridesharing service (when the end-user acts as transport provider itself).

To get some examples, it is possible to look at:

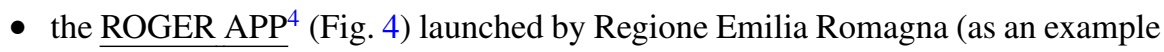
of the integration of static and dynamic data to provide multimodal and multioperator services on mobility (PT + parking) at regional level);

- the APP developed by the Municipality of Almada (Fig. 4) within INTERREG MED MOTIVATE project, as an example of trip diary registration and collection of end-users feedbacks;

- the Elba Sharing APP ${ }^{5}$ introduced by the Municipality of Portoferraio within CIVITAS DESTINATIONS project (see Sect. 5);

- Stadtnavi ${ }^{6}$ (Fig. 4) provided by the city of Herrenberg for route planning in Herrenberg region. The service covers PT, walking, cycling, private car use and carpooling.

\footnotetext{
${ }^{4}$ https://rogerapp.it/.

${ }^{5} \mathrm{https} / / /$ play.google.com/store/apps/details?id=net.pluservice.elbasharing\&hl=en.

${ }^{6}$ https://stadtnavi.de/.
} 


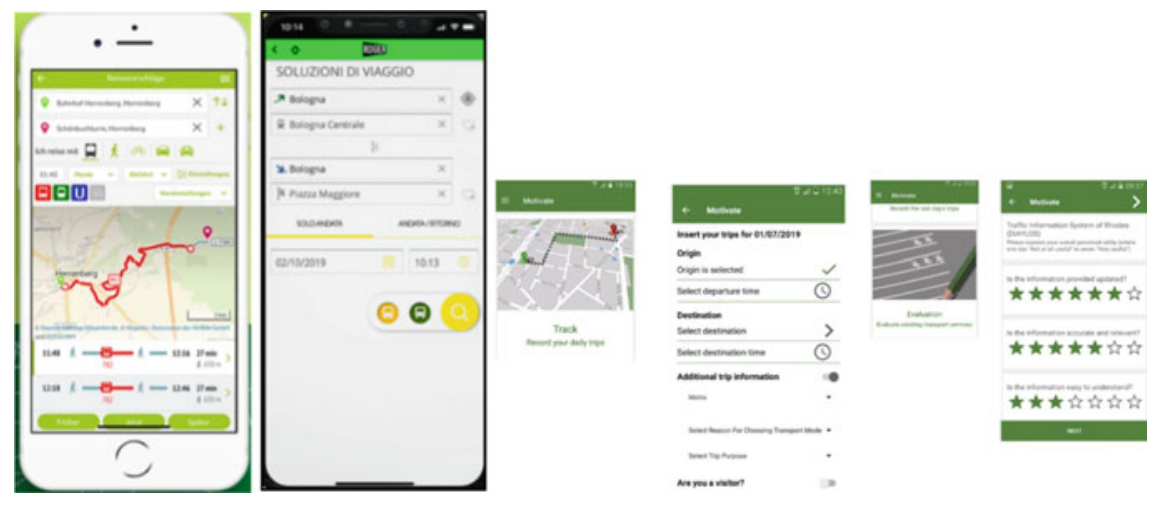

Fig. 4 ROGER, Almada and Stadnavi APP

As complementary consideration, it is possible to state that the choice of the APP category is also related to the specific context, end-users target and background conditions. To give some examples, the selection of the functionalities to be included can be driven by the relevance of the various end-users segments (in particular some functionalities may be targeted to specific segments such as elderly or people with reduced mobility, others may be targeted to receive feedback from passengers on the quality of the services $\mathrm{f}$ ), the opportunity to add the ticket purchase function depends on how easy it is to buy a ticket with other selling channels, etc.

\section{The Elba Shared Mobility Agency}

The SUMA concept aims to reconcile and enhance the two parallel axes of urban mobility (collective transport and flexible/ridesharing services) by testing and demonstrating different innovative mobility solutions to be integrated under its "umbrella" (Nelson \& Ambrosino, 2015). The concept can be tailored to different contexts selecting the functionalities and adapting them to the needs (Fig. 5).

One of the main measures of DESTINATIONS project was the development of the SUMA in Elba as centre for managing and making accessible several "on-demand and shared" individual and collective transport services, coordinating various actors and services supported by an advanced IT platform.

A large part of the MaaS initiatives in Europe has been implemented in urban areas (White Paper on Mobility as a Service (MaaS) and initially pushed by commercial operators (such as MaaS Global in Finland). When the implementation phase moved from early adopters to a more mature status, it has been found that Public Authorities and Mobility Operators need to take the leadership of MaaS initiative as they are the main data provider (a perspective on MaaS from Europe's metropolitan transport authorities, EMTA). The implementation of SUMA in Elba aims to adapt MaaS concept to rural areas (which have quite different needs compared to the urban area in 


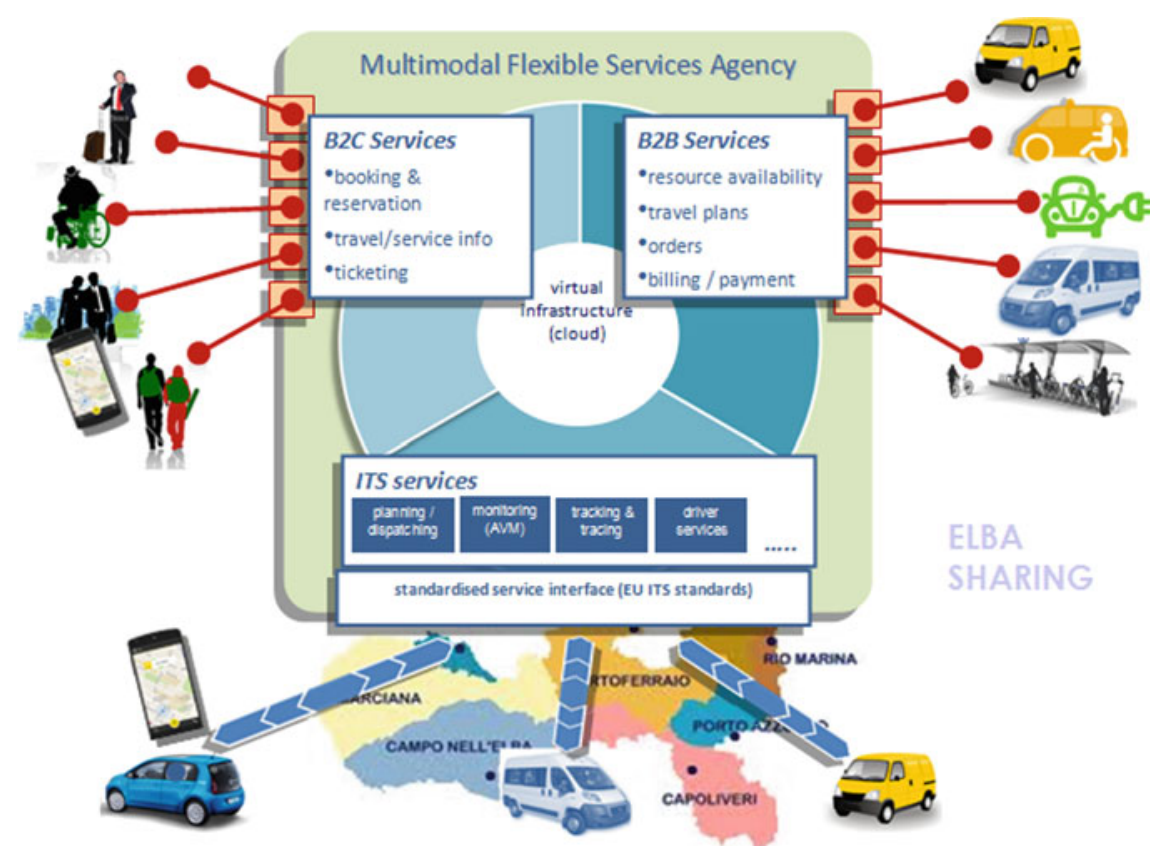

Fig. 5 Concept of Shared Mobility Agency (SUMA)

terms of flexibility of demand, type of mobility offer and mobility solutions). In large urban area metro/tram/light rail are the key transport modes, PT network is based on main axis and demand is more related to commuting habits. Moving to medium-small sized cities and rural area bus is the main transport mode and sharing (asset/ride) services are complementary rather than competitor of bus services. Demand is more dispersed in terms of destinations, time and purpose for travelling. Furthermore, MaaS implementation in Elba is strongly led by the Municipalities (Portoferraio) supported by the involved Public Transport Operators (Gini \& Ambrosino, 2019).

\subsection{Reference Context and Users' Needs Analysis}

Elba Island is located $10 \mathrm{~km}$ away from the coast and is the main island of the Tuscan Archipelago (Fig. 6). Consisting of seven municipalities, Elba has numerous towns and small settlements spread across the island with predominantly rural areas in between them. The island's PT services operate mainly along its key transport arteries.

Elba is one of the main tourist destinations in Europe, not only for Italians but also for foreign travellers coming from Central Europe (Austria, Belgium, France, Germany, Netherlands and Switzerland) and looking for blue sea, beautiful beaches 

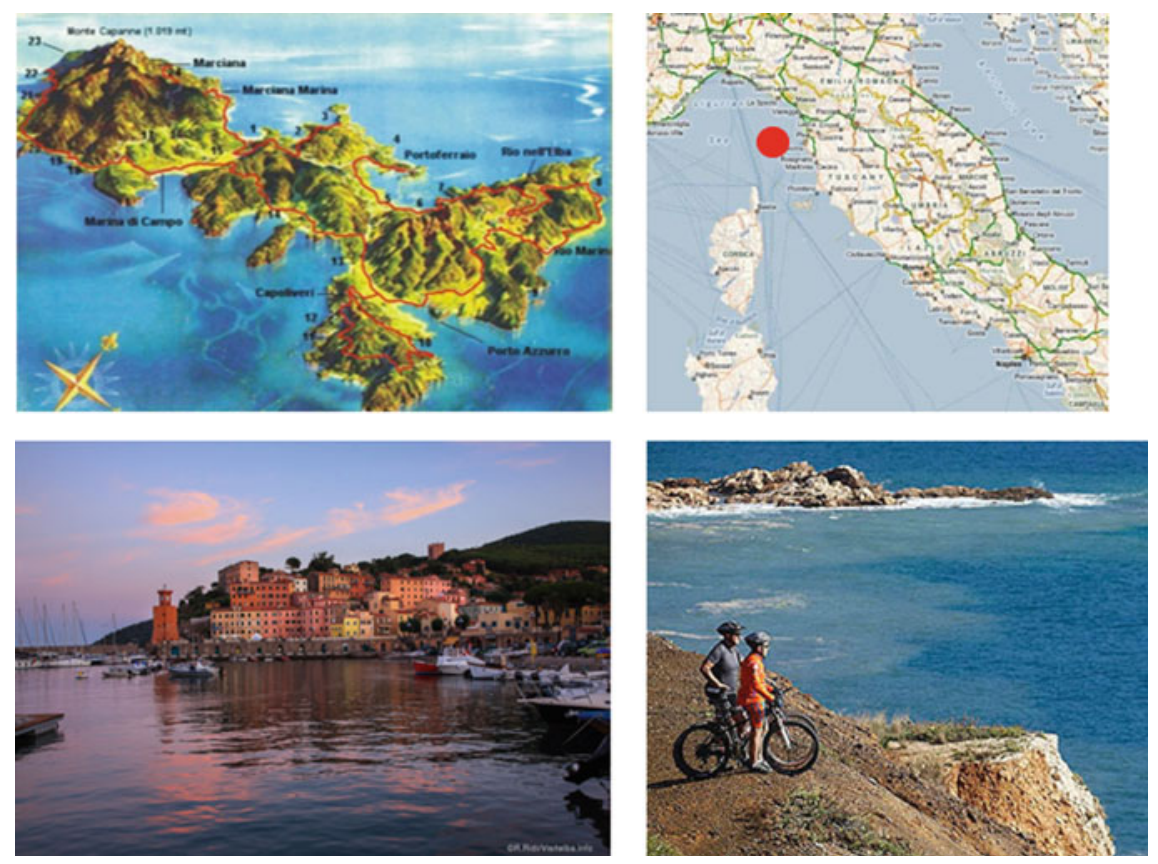

Fig. 6 Elba context and tourist attraction

and outdoor experiences. The annual number of tourists (pre COVID situation) is $450,000 /$ year with a daily presence of about 30,000 people/day bringing a $30 \%$ increase in transport demand, alongside a drastic variability for destinations (beyond the main transport network) and time (low-demand hours beyond peak hours).

Currently, the island's PT system cannot meet these needs and this situation is further exacerbated by the fragmented nature of Elba's mobility offer (including rental operators): services are uncoordinated and information spread across various sources affecting the way a tourist can access them. A coordinated mobility offer, including collective and private modes, is an added value in Elba, sustainability and overall accessibility and could also bring new job opportunities.

The problems that affected the mobility offer in Elba are (Fig. 7):

- High seasonal mobility demand (early morning to late night);

- Dispersed origins, few concentrated destinations (beaches, discos/bars, camping, museums and archaeological sites, etc.);

- Low use of PT services (only 14\% of overall trips); private cars and motorbikes are largely used but, in some cases, are not the most suitable transport mode due to parking scarcity and poor accessibility of a wide range of destinations;

- The offer of rentals (bike, scooter, car, boat) is increasingly high, but it fails for coordination.

SUMA provided answers to the identified local needs: 


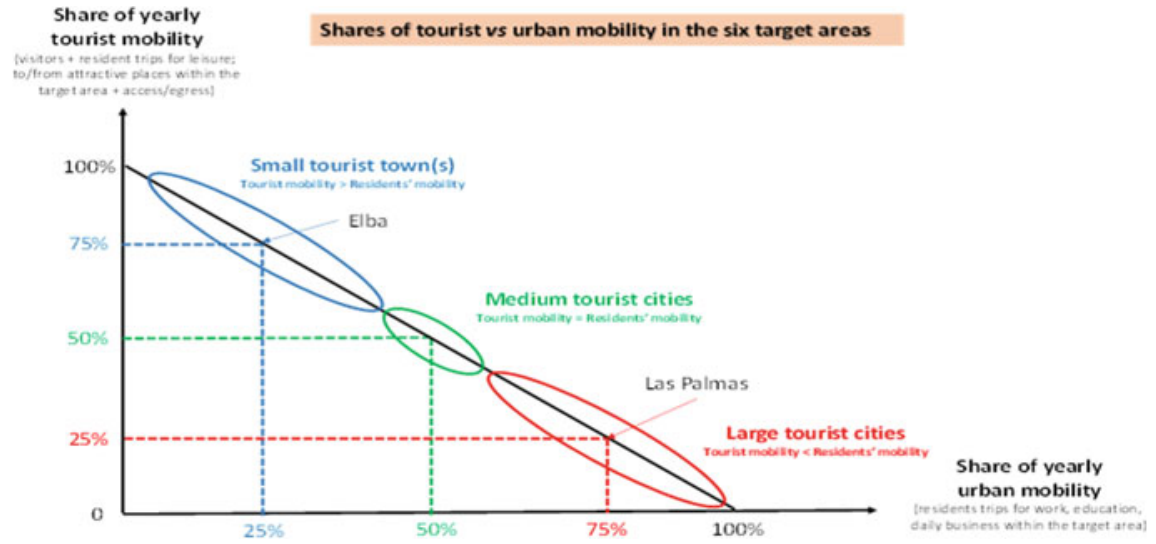

Fig. 7 Share of tourists against residents for the six destinations cities

- A coordinated mobility offer "brokered" by a unique Agency will be an added value in Elba attractiveness, sustainability and overall accessibility;

- The design of the Agency is based on the networking of the local vehicles (i.e. bike/scooter) operators on the island in order to optimize the available resources and to create a suitable offer to be integrated with PT;

- The user can act as mobility service contributing to solve the conflicts between the PT services and the individualized mobility.

The design of SUMA (carried out by MemEx) consists of three different levels:

- The technological platform supporting the Agency operation;

- The organizational and operational level for daily management;

- The business model for long-term sustainability.

The following sections, detail how each of these areas has been worked out.

\subsection{The Specifications of the Agency Platform}

The enabling technological infrastructure for SUMA is based on the emerging paradigm of the Internet of Services or Service Orientated Approach, providing several core facilities including:

- services for transport users (Business-to-Consumer B2C) enabling access to information, search for transport options, travel planning;

- services for the coordination of different ridesharing and mobility schemes and interaction with relevant operators (Business-to-Business B2B); 
- services supporting the interactions among different authorities and entities involved in mobility planning and control of transport services (Business-toAdministration B2A).

The main components of the platform are shown in Fig. 8.

- Open Data Layer accessing data from different sources, standardizing and aggregating them in order to enable the other functionalities and the provision of Open Data. Open Data Layer accesses to different data sources: the regional open data web portal provided by Regione Toscana (providing a scheduled timetable for all the transport modes in the region) and local databases (for rental operators);

- Infomobility Service Management providing multimodal aggregated info (static such as timetable and tariffs) and dynamic (real-time) including a journey planner. The infomobility services will be provided on APP and web portal;

- Shared Service Management allowing the matching between demand and offer for sharing trips;

- Operators networking enabling a centralized "window" for the offer of rental services.

These functionalities represent the first core of SUMA which can evolve in the future up to a "full" MaaS concept for rural/peripheral areas (including the integrated payment).

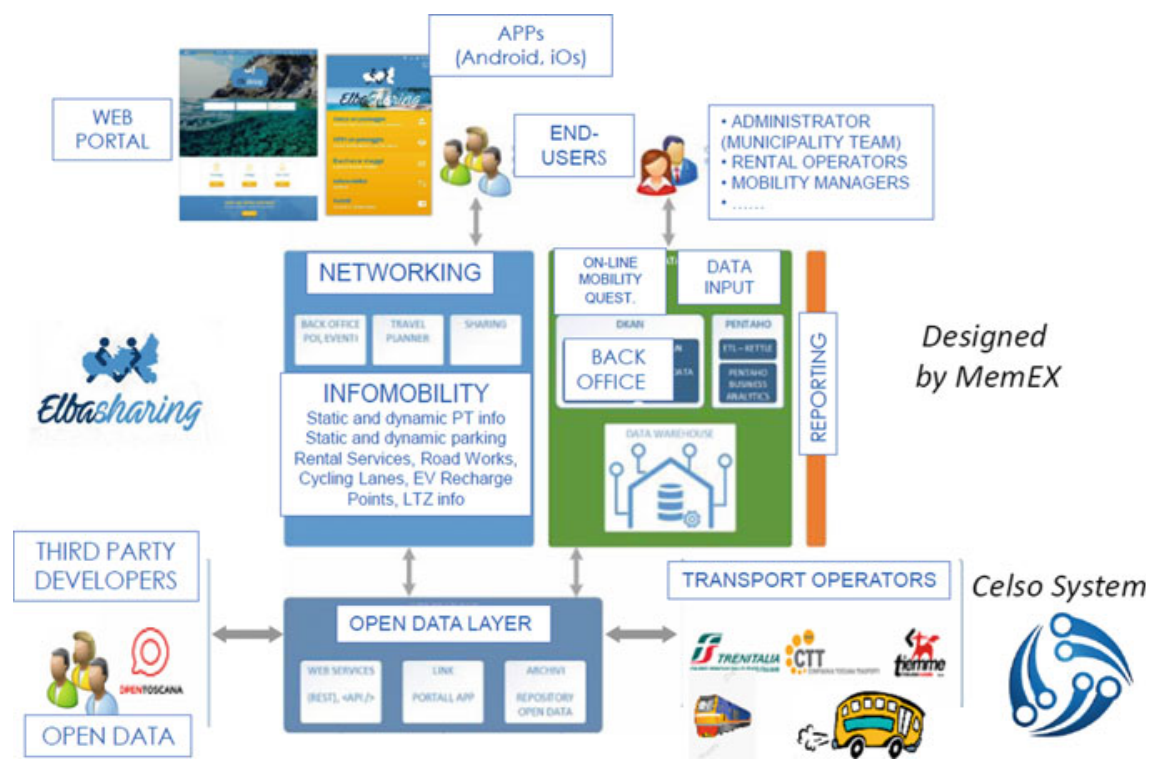

Fig. 8 Functional architecture of Shared Mobility Agency for Elba 


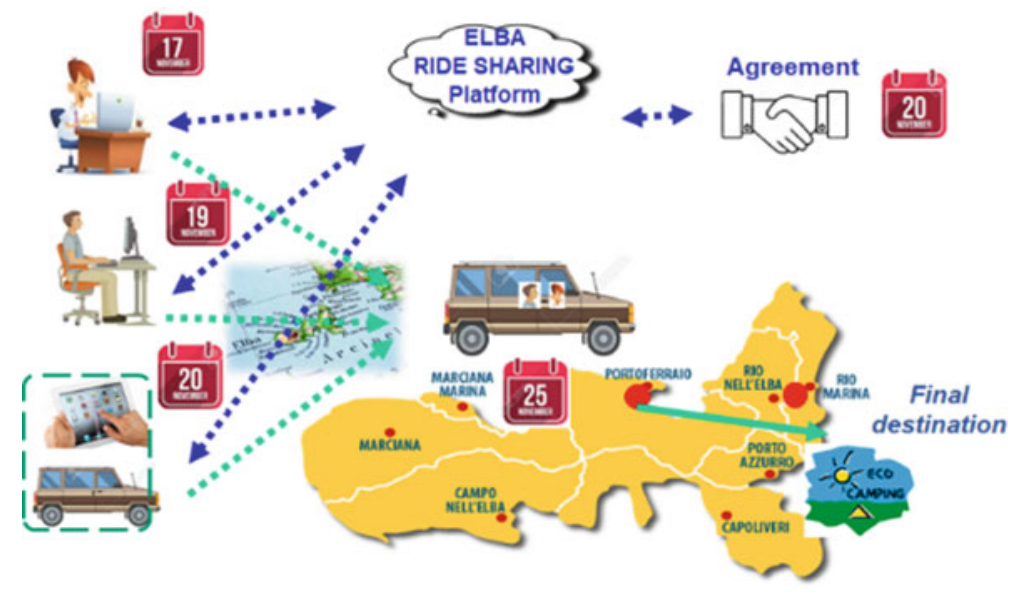

Fig. 9 Trip sharing planning

\subsection{Use Cases}

Users registration is required to use the functionalities for the management of ridesharing services. The registered data are stored and handled in compliance with the national privacy regulation and EU requirements (General Data Protection Regulation, 2016/679). The management search engine function shows to the user (Fig. 10) the options to combine ridesharing offers and requests with the use of PT and the offer of rental operators. Ridesharing possibilities are numerous, including sharing a trip when a user is on the ferry; planning shared trips in advance, and sharing a taxi trip Fig. 9). These scenarios can also be managed through a notice board on which passengers and drivers can publish their trip share requests and offers.

Features such as journey tracking and user evaluation of vehicle drivers will also be included to improve passenger safety. Key use cases will be detailed in the presentation.

\subsection{The Agency Implementation and Business Model}

The call for tender to subcontract the platform has been prepared in OctoberNovember 2017 and launched in December. The ITS platform has been purchased as a supply including technical services supporting the implementation, training of operators and a three-year warranty. The bidder proposals (from three national IT providers) were received in February 2018 and the winning was awarded in June 2018. The Contract between the Municipality of Portoferraio and the awarded bidder was signed in September 2018. A first prototype of the Elba SUMA was released in 2019 including a first core of scenarios for the management of sharing services, 


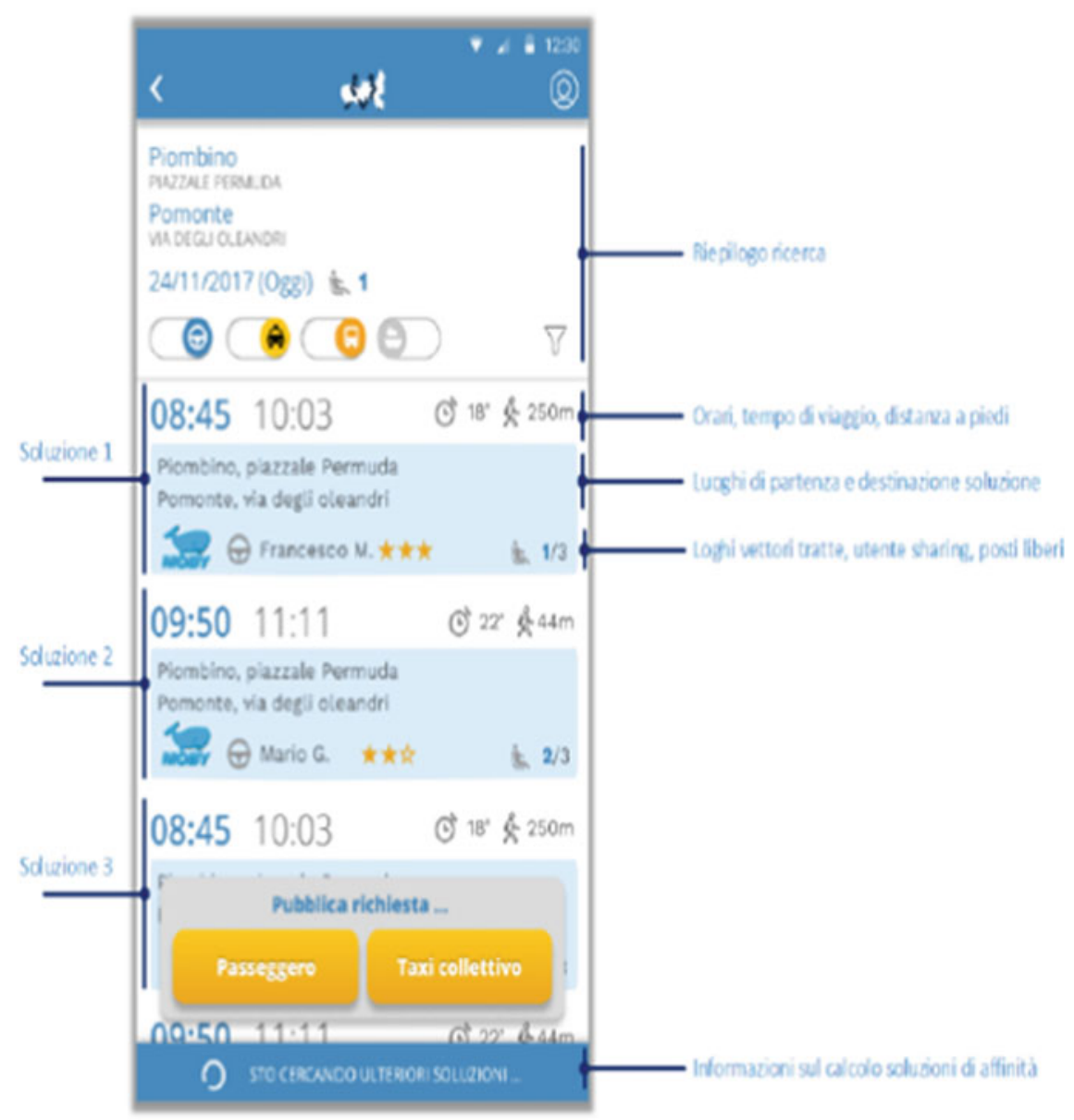

Fig. 10 Visualization of trip option by search engine

infomobility and networking. Two further versions of the IT platform were released during the 2020 winter and the final version with full functionalities is available from June 2020.

In the meantime, the operational procedures for the management of the Agency have been defined:

- Monitoring of data gathering processes from connected sources;

- Updating/management of data repository for SUMP (from "paper" surveys);

- Updating/management of static contents;

- Engagement of the networked operators of vehicle sharing services.

The following cost categories have been considered: internal staff (two operators are estimated to operate the Agency), software maintenance, utilities and promotion. 
Moreover, the costs of specific technical support to Portoferraio Municipality should be also taken into account.

Two main segments of target customers will use SUMA: tourists and residents. Other stakeholders involved in the use of the Agency are rental operators, commercial operators (i.e. discos, restaurant, shops, etc.), third-party developers accessing the Open Data for their applications, Public Administrations, consultancy companies and professionals accessing data/survey stored in the Open Data Layer.

The economic viability of the Agency, after the end of the CIVITAS DESTINATIONS project, could be guaranteed by the external revenues deriving from these alternatives:

- an annual fee (to be established based on the performance of the first two years of operation), to be requested at the time of registration to users (both users and commercial activities/operators). Assuming that $5 \%$ of these are registered, equal to about 22,000 people, a minimum contribution of $€ 3$ per registration could be reasonable, for a total of about $60,000 €$ annually;

- an annual contribution from renting operators (bikes, cars, scooters, boats, etc.) that are included in the network through the platform (with the possibility of dynamic interaction);

- a contribution from interested commercial operators (e.g. discos, restaurants, supermarkets, etc.) to be indicated in the platform as primary points of departure or arrival of "shared trips", in order to increase their attractiveness and safety level;

- possible contributions from local administrations or consultancy companies interested in the documentation and data on mobility and transport accessible through the Open Data Layer of the technological platform.

\subsection{First Results}

The final version of Agency was launched, in June 2020.

Unfortunately, the COVID-19 affected the possibility to carry out an extended and deeper test of the platform and Agency functionalities both from the specific residents' groups (especially students and village representatives) and by the different tourists available to leave the car at the hotel and to use the different mobility options integrated by the PT services offered by the SUMA.

In any case, the scheduled tests have been envisaged with a two steps procedure:

- A first session carried out by a selected group of people (including some tourists) in order to identify main problems (if any) which can prevent the use among a wider group of testers;

- A second session open to a wider group of testers recruited through specific engagement actions among residents: students, tourist operators, etc.

The first step, despite the difficulty of COVID-19, was carried out to make the first updates for the launch of the second version of the platform. 
The promotion of the Agency and the related APP is scheduled with the second test steps focused on the improvement of user experience.

The launch of this version of the platform will allow checking which are the impacts of SUMA in terms of users and then the overall success of the initiative. The initial estimation, also based on the analysis of this (COVID-19) Summer 20 is to get at least $5 \%$ of the tourists visiting Elba (equal to 22.000 people). A minor part of users should also come from the visitors (to be added to the previous figure).

Once SUMA is entirely in operation, the allocation of resources estimated in the design phase will be verified and tuned together with the responsibilities and working procedure for daily management.

The feedbacks coming from the Agency operation (in terms of users, operational costs and level of engagement of stakeholders, i.e. the rental operators) will allow to validate the business model defined in the design phase and to adjust the figures if necessary.

\section{Conclusions and Recommendations}

The above sections introduced the role of innovation and digital solutions in touristic destinations and rural areas characterized by a low and variable mobility demand. For each set of digital solutions, some common practice recommendations have already been provided.

In this section, some other key recommendations are provided to Transport and Mobility Operators and/or Public Authorities (Municipalities, Agencies, etc.) aiming to implement digital solutions especially the APP for the infomobility and service management.

As already stated, the market of APPs is too much varied; therefore, the choice of a specific app should depend from one side on the different targets and required functions and from the other side on the different data sources to be linked.

For this, the concept of APPs "Jungle" and the categorization of the APPs was introduced, in order to support user needs analysis, to identify the key functions and screening the same "jungle". Therefore, the selection of APP typology and functions should be based on some criteria, among the others, related to objectives of the service implementation, target end-users, main needs in the accessibility to PT, institutional context and cooperation levels with the different stakeholders or with the other digital solution initiatives. These criteria should be analysed taking into account also the background conditions (i.e. available data, data collection tools, existing IT systems acting as data provider, system responsibilities etc.).

For the relevant issue related to "how" to get data the interrelation between open data and centralized data source should be explored in detail. In particular it should be clarified if the required data are already published by the owner or if required data coming from different services/operators have already been stored in a common data source at different levels (local, regional) to be interfaced. Another macro aspect that should be taken into account for defining the suitable digital solution based on APP 
is to require close cooperation among the involved providers/stakeholders in case the needed data sources are managed by different stakeholders or operators: it is essential that one stakeholder (i.e. the Public Administration, at city level) coordinates the different actors involved. The availability for cooperation by the technical provider of legacy systems and background applications is also required.

Special attention must be paid to the design of attractive graphical layout of APP/web portal; it is particularly important to consider the time required for an agreement on this aspect when a relevant number of local stakeholders are involved.

Even if the APP is well designed and duly implemented, its diffusion, use and acceptance can hardly be achieved if a specific promotion is lacking; therefore, it is strongly recommended to define and develop a relevant marketing strategy and actions.

Moreover, the complexity should not be underestimated, in particular:

- the evolution of APP layout and functionalities over time in terms of: ongoingneeds, data integration, contracting, acceptance, etc.;

- the quality of data and reliability of the functionalities in terms of performance indicators, testing procedures, data maintenance, etc.;

- smooth operation in terms of monitoring procedure for data accessibility, the responsiveness of operational procedure, back-office activity and operation/interfacing procedures.

Last but not least, the contract requires specific attention, especially in the case of digital solution procurement and implementation. The main aspects to be paid attention to are the following, among the others:

- modularity and future scaling-up of the solution not only from the technical solutions adopted, but also from the contractual point of view, thus avoiding extra-costs (i.e. validity of software license without time restrictions and without limitations of data sources interfaced);

- continuous support by the IT provider during implementation (interfacing the legacy providers, on-site activities for integration, installation and testing, maintenance);

- implementation milestones should be defined in order to manage step-by-step payments on the basis of the results of the testing procedure (functional and performances verification) to be carried out during the realisation phase;

- final payment and warranty should be released at the final acceptance of the whole system.

Finally, besides the above recommendations a "common sense" indication related to complex digital solutions implementation, like SUMA, is to keep the realisation approach simple. 


\section{References}

Ambrosino, G., \& Gini, S. (2016). Mobility as a service: The Italian Style. In: ITS passenger transportation systems and services sponsored by ITS America and American public transportation association, 95th TRB. Washington.

Ambrosino, G., \& Gini, S. (2018). Implementing a new business model for flexible mobility. Intelligent Transport on-line Magazine. Retrieved from https://www.intelligenttransport.com/transp ort-articles/68818/the-flexible-mobility-concept/.

European Association of Metropolitan Transport Authority (EMTA). (2019). A perspective on MaaS from Europe's metropolitan transport authorities. Retrieved from https://www.emta.com/ spip.php?article1319\&lang=en.

Gini, S., \& Amborsino, G. (2019). "MaaS approach in Elba: The shared use mobility platform" Booklet. Retrieved from http://www.memexitaly.it/wp-content/uploads/2019/04/CivitasDestinat ions_v2_April19.pdf.

Gini, S. (2019). Shared use mobility agency: Concept and implementation in Elba. In: Destinations Technical Workshops, Elba Project Meeting, Portoferraio. Retrieved April 10, 2019.

H2020 Urban Project. (2018). White paper on mobility as a service (MaaS). Retrieved from https:// jpi-urbaneurope.eu/app/uploads/2018/09/JPI-UE_MaaS_white_paper2018.pdf.

Hietanen, S. (2014). 'Mobility as a Service'-The new transport model? ITS \& Transport Management Eurotransport. Retrieved from http://www.itsineurope.com/its10/media/press_clippings/ ITS\%20Supp_et214.pdf

Nelson, J., \& Ambrosino, G. (2015). Shared use mobility services in a mid-size historic town. In: Annual Polis Conference. Retrieved November 2015, Bruxelles.

Open Access This chapter is licensed under the terms of the Creative Commons Attribution 4.0 International License (http://creativecommons.org/licenses/by/4.0/), which permits use, sharing, adaptation, distribution and reproduction in any medium or format, as long as you give appropriate credit to the original author(s) and the source, provide a link to the Creative Commons license and indicate if changes were made.

The images or other third party material in this chapter are included in the chapter's Creative Commons license, unless indicated otherwise in a credit line to the material. If material is not included in the chapter's Creative Commons license and your intended use is not permitted by statutory regulation or exceeds the permitted use, you will need to obtain permission directly from the copyright holder.

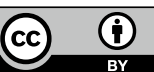

